\title{
A child's perspective of bidirectional impacts of mental illness in families: "It's like a cold it goes from one of us to the next"
}

\author{
Michael Frederick Naughton*1, Darryl Maybery ${ }^{1}$, Melinda Goodyear ${ }^{1,2}$ \\ ${ }^{1}$ Monash University, School of Rural Health, Australia \\ ${ }^{2}$ The Parenting Research Centre, Australia
}

Received: September 24, 2018

DOI: $10.5430 / c n s . v 7 n 2 p 8$
Accepted: November 19, 2018 Online Published: November 26, 2018

URL: https://doi.org/10.5430/cns.v7n2p8

\begin{abstract}
Objective: Investigations into the influence of mental illness in families concentrates on how a parent's mental illness has an effect on their child, but we now know over two thirds of children with a mental health issue also have a parent with a mental illness. This study examines experiences of these children.

Methods: Thirty-eight children were interviewed, including two sibling groups. Interview transcripts were analysed using interpretative phenomenological analysis with a number of themes identified.

Results: It was clear from children's accounts that family life presents some unique challenges because of co-existing mental illness. These included social challenges; school issues; and family interactions. Children also postulated ideas on the support that they considered helpful for comparable children and families. The latter included coping strategies, experiences of professionals and support that they would have liked.

Conclusions: The voices of these children indicate that interventions should not be considered in isolation and that it is important to focus on bidirectional influences of mental illness. Understanding the perceptions and interpreted realities of children in these families will facilitate more successful outcomes for the whole family. Providing a family-focused, bidirectional approach, is an important initial phase in helping children manage where mental illness is a ubiquitous feature for multiple family members.
\end{abstract}

Key Words: Children, Mental illness, Bidirectional impacts, Perspectives, Family

\section{INTRODUCTION}

Estimates of the prevalence of parental mental illness have varied with studies reporting rates of $21 \%-23 \%,{ }^{[1]} 32 \%{ }^{[2]}$ and $50 \% .{ }^{[3]}$ A recent review of the prevalence of parents attending adult psychiatric services estimated between $12 \%$ to $45 \%$ of service users to be parents ${ }^{[4]}$ with four studies showing rates between $36 \%$ to $38 \% .^{[5-8]}$ These figures indicate approximately one-third of adult psychiatry service users are likely to be parents. These data suggest where a parent has a mental illness children are at increased risk of developing mental illness themselves.

In recent years there has been an intensification in research attempting to understand the prevalence of mental illness of parents of children presenting to mental health services. Studies have estimated varying degrees of parental mental illness of Child and Youth Mental Health clients with numbers ranging between $30 \%$ and $42 \% .{ }^{[9-11]}$ However, in regional Canada, Baker and Lees ${ }^{[12]}$ found $70 \%$ of children attending

\footnotetext{
*Correspondence: Michael Frederick Naughton; Email: michael.naughton@monash.edu; Address: Monash University, School of Rural Health,
} Australia. 
a Child and Adolescent Mental Health Service (CAMHS) had a parent with a possible mental health concern. The current study extends an earlier investigation of CAMHS families that determined almost $80 \%$ of these children were living with a parent with mental illness. ${ }^{[13]}$

A systematic review by van Santvoort et al. ${ }^{[14]}$ found a connection in the research between parental and child disorders impacting on the well-being of both parents and children. ${ }^{[1,15]}$ Boursnell ${ }^{[16]}$ suggests parental mental illness impacts on parenting capability and Hautamäki ${ }^{[17]}$ noted maternal unresponsiveness and low parental sensitivity where there is mental illness. The interaction, and resulting effects of mental illness in families, is usefully explained in the Crossing Bridges Family Model. ${ }^{[18]}$ The model outlines the consequence of the child-parent dyad in disturbing, even intensifying, child and parent mental health issues.

Transgenerational influences of behaviour, communication and emotional responses have been found to impact on the next generation. ${ }^{[19]}$ The quality of relationships in families influence subsequent relationships and functioning of children, with patterns of behaviour transmitted from generation to generation. Family secrecy around emotions, in turn, shape children's emotional experiences with strong links found between grandparent's emotional attachment and their grandchild. ${ }^{[20]}$ Studies have also shown an active link between adult attachment security and infant security. ${ }^{[21-23]}$ The Bailey et al.'s study of 184 mother-infant dyads concluded that "intergenerational configurations of attachment might be linked to the elaboration of disorganisation". [24] (p. 444).

Considering co-existing family mental illness through the lens of the sociology of childhood adds to the discourse. Children are recognised as active participants in their own environment interacting and creating a culture they share with others. As social actors' children are active in their construction of the world and can influence that world. ${ }^{[25-27]}$ With children seeking to be effective family members and wanting to understand social rules and relationships the influence of parental mental illness cannot be underestimated. Children as young as two are capable of asserting themselves and causing parental conflict and emotional dysregulation. ${ }^{[28]} \mathrm{A}$ situation possibly made worse through the lens of mental illness. Children actively contribute to their world construction as social actors able to evaluate and reflect on things happening around them. ${ }^{[29,30]}$ Importantly, relationships between adults and young people are distinguished by a disparity in power. Children have a dependency relationship with adults whether they want it or not and a child's socialisation is often constructed to fit into a particular social role. ${ }^{[31,32]}$ From this

Published by Sciedu Press perspective, it might be argued that a child living in a world consumed by parental mental illness is likely to adapt to that environment in very particular ways.

Whether children's risk of mental illness is a consequence of parental attachment issues, is shaped by transgenerational factors, or is mitigated by a child's constructions and biological factors is a matter for further consideration. This study takes a child-centric approach in examining the experiences of children with a mental illness living with a parent with a mental illness.

\section{Methodology}

Community mental health clinicians from a regional mental health service were engaged to identify children from their caseload, over the age of 12 years, who also had a parent with a mental illness. The identified families were invited to participate in a qualitative interview study.

\subsection{Participants}

From 37 volunteer families, there were 38 children interviewed that included two siblings (see Table 1). One child withdrew consent at the member checking stage. Of these families, $59.5 \%(n=22)$ lived in regional settings, with the remainder from rural areas. Notably, $24.3 \%(\mathrm{n}=9)$ of the parents were employed, $45.9 \%(n=17)$ on a disability support pension due to a mental health condition and $8 \%$ $(n=3)$ were seeking employment, the remainder were on other types of benefit. Parents ranged between 30 and 55 years of age with nearly half within the 36 to 45 age bracket. There were 32 mothers and 5 fathers. Children ranged in age from 12 to 23 years: $45 \%(n=17)$ aged between 12 and 14 years; $42 \%(n=16)$ aged between 15 and 17 years; $13 \%$ $(n=5)$ were aged over 18 years. Parents had either current or past involvement with adult mental health services with all children engaged with CAMHS. The primary diagnosis of the children was depression $(40 \%, \mathrm{n}=15)$ and depression and anxiety $(34 \%, n=13)$. Of the total $11 \%(n=4)$ had anxiety alone with $11 \%(n=4)$ with co-morbid ADHD and anxiety. Only $3 \%(n=1)$ had a diagnosis of psychosis with one other child diagnosed with high functioning autism.

Children were interviewed without the parent present in the room, though parents remained in close vicinity. Monash University and community mental health service ethics committees approved the research.

\subsection{Interviews}

The children chose when and where they wanted the interview to occur with most interviewed in their own home. The principal interviewer was an experienced child and family clinician with over 20 years' experience. During the in- 
terview process support and supervision was provided for of the children and followed the format of the preceding the principal researcher from a team of clinical child psy- parent interviews. The prompts used were: (1) Please try and chologists. Support for parents and children remained with the treating mental health team. Prompting questions were developed through a focus group of consumer advocates and mental health clinicians. Three open-ended facilitating prompts were used to encourage the descriptive discourse describe your experiences when you feel (mentally) unwell and when your mum or dad is (mentally) poorly; (2) Please describe any supports you and your family have had; and (3) Based on any support you have had what, if anything, do you think could be done better?

Table 1. Demographic information of children, parents, grandparents and communities

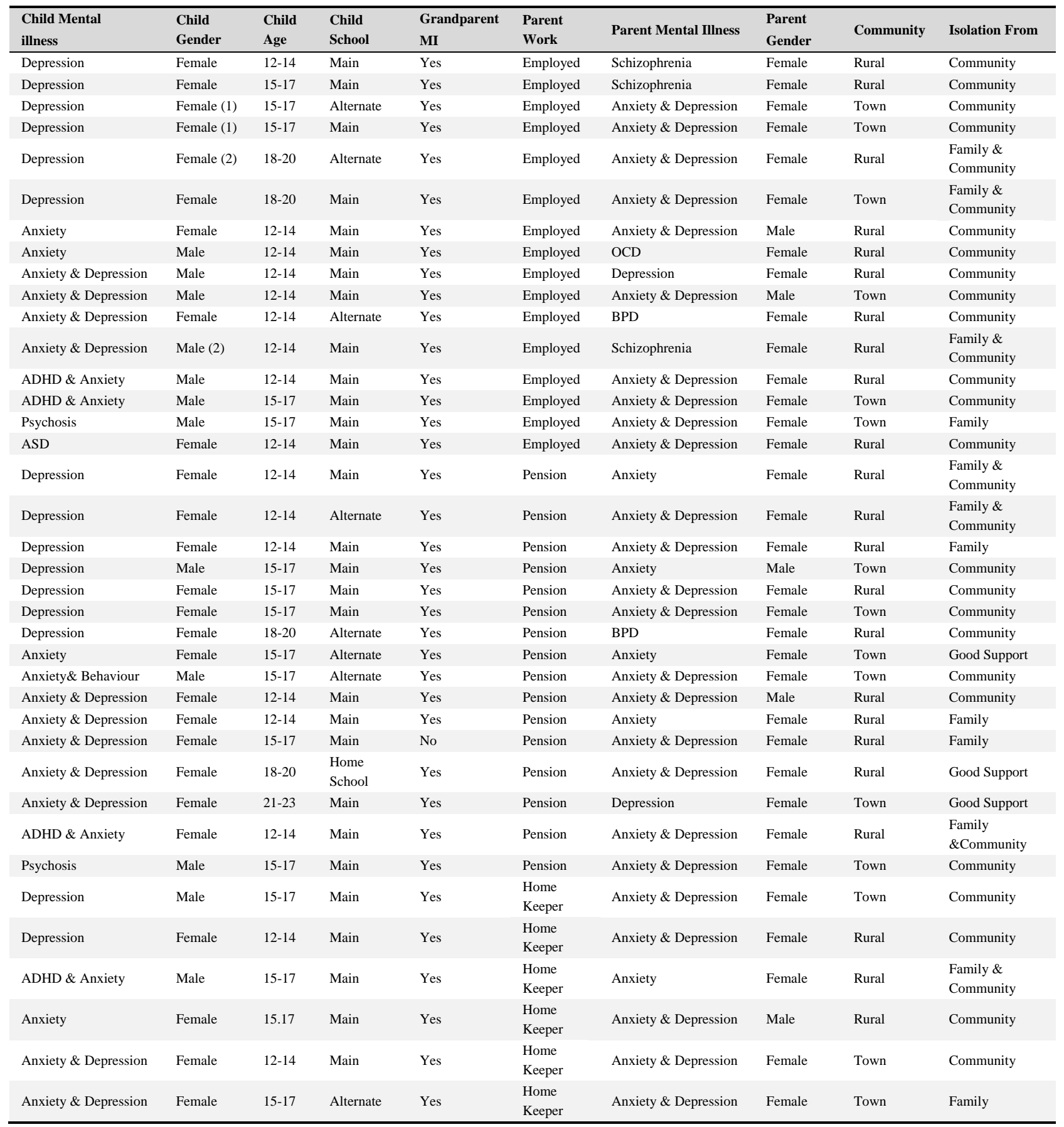

Note. (1) \& (2) - Two Sibling groups 
The purpose of the research was explained with the Information Sheet offered. Both parents and children consented to being involved. It was emphasised on a number of occasions that they could withdraw from the research at any time prior to transcripts being de-identified. The procedure for voice recording was explained with children provided opportunities for clarification and to ask questions. Dialogue length was wide ranging varying between the shortest at 20 minutes and the most extensive at 90 minutes.

Based on prior experience with their parents, the interviews with children were carried out using an approach allowing the children to build their own story around the three prompts. The researchers sought to understand, through an interpretive approach, how these children's active involvement in the family formed part of the creation of their family experience. It was also important to understand how these children added to the construction of their own childhood. Our approach was based on the humanistic ideas of Rogers ${ }^{[33]}$ supporting greater openness and ensuring experiences could be effectively understood. We adapted our methodology to best meet the emotional exigency of the children (see Figure 1) ensuring we were therapeutic and non-threatening. ${ }^{[34]}$

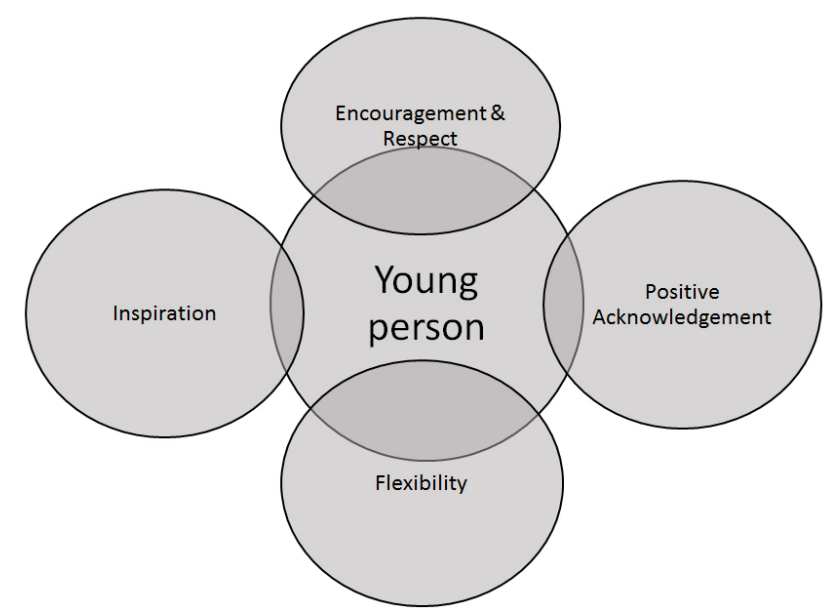

Figure 1. Approach to support the engagement of children with mental illness

Member checking was conducted with the children sent a copy of their original transcripts. Seven of the children, all from the 15-17 years group, asked for a follow-up interview to discuss the transcripts. While transcripts were not amended, children provided further clarifying ideas that were added to the original data.

\subsection{Data analysis}

Voice recordings were transcribed professionally with the text returned to the research team for thematic analysis. The first step was to integrate responses into single narratives within each prompting area before completing an inductive thematic analysis. ${ }^{[35]}$ Individually research team members coded the responses before then being collated into a context for inclusion or exclusion. Utilising NVivo for Mac (Version 11.4.3) the transcriptions were again coded to establish similarities and crossovers. By the very nature of the phenomenological descriptions provided by the children codes were not mutually exclusive and there were a number of instances where codes were matched to multiple themes. Word mapping in NVivo was used to further refine the coding process and a matrix was used to provide illustrative extracts for each theme. To assist in capturing any patterns transcripts were read several times. This was important to ensure meaning was not lost and children's interpretations and experiences of reality were effectively encapsulated. Ideas were determined from the frequency in which words and phrases occurred. Concepts were then amalgamated and classified independently by two of the authors who together agreed upon the core themes. Any word and theme uncertainties were discussed, and consensus reached.

\section{Results}

Just over half the children stated it was mid-way through primary school when they first realised their family was different. Several recalled recognising there was family mental illness at about age 7 years with only a few not realising until they were teenagers. The following outlines themes from the interviews.

\subsection{Children's experience of their own mental illness}

Children described the manner in which mental illness impacted on daily life and interactions. They described feelings of frustration and anger even resentment at being burdened with mental illness.

“... when I'm anxious I find it really difficult to remember anything..."

Children defined mental illness as overwhelming and despite this, they would try to hide their mental illness from others. Overpowering and consuming, mental illness caused anger at not being able to be "normal" with guilt and anger towards parents. Feeling sad and alone were also commonly reported.

"I more like hide in my room ... ignore reality and just sit in bed, just not doing anything."

For over three-quarters of the children there was an unease about how their parent understood them. They also believed it took some time before parents realised they had a mental health problem. One child described this as:

"Before I figured out what was wrong with me I felt like my mum didn't love me ... she had to put me as low priority 
because she had to look after my stepdad and my sisters first. We didn't know what was going on with ourselves."

\subsection{Children's experiences of their parent's mental ill- ness}

Feeling rejected and abandoned by their parent, when their parent was unwell, was commonly reported. A third of the children had experienced their parent being assessed at an emergency department where the children felt "lost" and "unsure". A particular concern was not being told what was happening. A similar scenario occurred when mental health clinicians visited homes. Having clinicians visit was reported as increasing stress and as having a negative impact on parents. Children recognised ambulance services or police were worried about them but due to the acuity of their parent's presentation the focus of intervention was concentrated on the parent. Some found themselves suddenly being cared for by other family members or family friends, and this increased their anxiety and sense of insecurity. Uncertainty and anxiety also occurred when considering the need to get outside help for their parent.

“... she wasn't accepting outside help, and it was hard ... where do you make that point of saying 'okay you're coming (to hospital) now'. And so it got quiet, she got, like she... deteriorated before we actually took her to the hospital."

Children reported parents becoming wrapped up in themselves when unwell, often not caring for anyone. All the children described in great depth having to "modify" their behaviour to avoid their parent becoming upset and unwell. A common comment being:

“... you have to do it right, and if you don't do it right then he gets really stressed and upset and yells at you, and so he did that a lot, obviously I wanted to do things to keep the peace."

Children described a sense of rejection when their parent was unwell, and this was particularly felt in primary school years. Feeling a sense of duty to protect their parent was common as they understood parental actions were not within the parent's control.

"she didn't want to be aggressive ... so when she'd suddenly get emotional and stuff she'd lash out and whack us with a wooden spoon or something, there were a couple of times where it got a bit heavy-handed... she was just freaking out cos she was feeling [mentally] unwell, and it's like she didn't know what to do."

It was also suggested that hospital admissions amplify children's sense of rejection:

“... my brother had just been born, and my mother went into [psychiatric] hospital for a stay - it seemed like forever. No one ever talked about it or bothered to explain things. I knew it wasn't good for her and that stressed me out even more."

Even when these children sought to appease their unwell parent, they felt consumed by guilt over what they should do: they spoke of an underlying fear about how they should respond.

"I guess that's the problem with having a parent with a mental illness - you have several parents in one body-you have your unwell one, and you're depressed one; you're manic one, and you're always treasure hunting for that little bit of the parent that you know loves you."

Commonly the girls, and some boys, described having to take over the parenting role when their parent was unwell. Responsibilities included easing sibling stress, paying bills, making meals and trying to keep a family routine. Once parents calmed, and the mental illness had become more manageable, girls spoke of turning to self-injurious behaviours to manage their own distress and dysregulation. Boys described anger and using bad behaviour as a response to parental mental illness.

\section{The bidirectional impact of mental illness}

Children commonly described the "family infection of mental illness". They explained how their parent's mood caused their mood to change and how anxiety followed this "infectious" pathway. Several children spoke of stress in the parent causing stress in themselves. They recognised when they were unwell that might cause their parent to become unwell. Sometimes increased anxiety and lowered mood were described as concern for the parent's well-being.

"I start to feel sad, and I start to feel desperate to try and make her feel better... When everyone is grumpy I get very grumpy, I just get mad. It's like pretty contagious... I would just worry and worry and that made me really sad."

Universally anxiety was described as worse than their parents. Despite adapting and being better able to manage with increasing age they described hyper-sensitivity to parental mental illness.

"When she was unwell I didn't have her to protect me because if she's scared then obviously the thing that's making her scared is some huge thing that I am useless against if she's useless against it. I didn't feel protected or safe when she was anxious. She will say things that are coming from her anxiety not from logic and then I just get more anxious myself."

They described being attuned to their parent but struggling with the parent's lack of understanding and empathy when trying to discuss mental illness. Family life was explained as

ISSN 2324-7940 E-ISSN 2324-7959 
a particular way of living.

“... my stress would come out when I went to bed because I would not be able to go to sleep ... or when I went to sleep when I woke up that morning I had wet the bed."

A further bidirectional influence was the sense of living like separate people in the same house. Importantly children behaved in ways to reduce stress and anxiety, and to avoid any deterioration in their parent's mental health which had consequences for their own mental health. Frequently they described taking these emotions to school showing anger or withdrawing.

\subsection{Children's experiences of support}

A core area of feedback from interviews focused upon what could broadly be termed Experiences of Support. This could be broken into four key areas of school, coping, experience of professionals and support that they would have liked. These are outlined in subsections below.

\subsubsection{School experiences}

School was seen as both a saviour and/or an aggravator. For most, it was a negative factor. Children felt stigmatised because of their mental illness and additionally stigmatised as a result of parental mental illness. The experiences they portrayed were of being ostracised or labelled as "weird" and "different". Stigma was exacerbated by a lack of understanding or awareness of the many issues they confronted because of parental and personal mental illness. Children became horrified when their parent came to the school because they reported an increase in negative talk about them from both teachers and peers. The issue of stigma made school a horrible experience that impacted on their ability to focus on school work and affected their own or their parent's mental illness. If they were unwell, they reported being unable to think about school work and for some even to hear the teacher. When they sought space to settle their thinking, they described usually being declined. When well the children spoke of worrying about their parent, would they be well when they got home or how would their parent cope without their support? For most children the bidirectional influence had a dual effect.

“... when I was at school I was actually at my worst point in my life. I was at the point where I was wanting to commit suicide and I had no friends and I was being bullied all the time. I talked my mum into putting me on this home-schooling program because I was able to help her with her stuff [- mental illness]."

Another noted:

“They don't understand me at school. And yeah, there's not Published by Sciedu Press much help I can get from school, because I feel like just none of them care. My teacher will notice but he won't do anything. Or like, I'll be crying, or I'll come out of the toilets teary-eyed or something like that, from having a panic attack, and no one will notice or help."

Peer relations were difficult with several describing being isolated from their peers. Half thought it was their parent's mental illness causing peers to avoid them, others thought it was because of their own mental illness.

"Friends would just disappear. One minute they're there and then the next minute they're not. And they just, they don't care."

For a few, school was a positive experience providing escape from parental mental illness and a place where they would get help. Having specific mental health support in the school reduced some of the negativity they experienced and ensured their family was understood. Connecting with likeminded peers helped children feel better understood. A third of children had at least one friend they could confide in and who was understanding of their personal and family challenges. Particularly useful were friends who accepted children's specific experiences and family situation.

"So that was always something my sister and I both had real phobias about being seen as being anything other than completely normal..."

\subsubsection{Children's strategies for coping}

A variety of strategies were reported with giving space a common approach, usually going off to a private area. $\mathrm{Mu}$ sic was also an important strategy either listening, playing or singing. Video games provided release from both their own and their parent's mental illness with over two-thirds believing this escape was leading to a problem.

Parentification was both a necessity and obligation that they reported as adding to stress and impacting negatively on their mental health. The burden of being a surrogate parent becoming a contentious and often conflicting issue. Getting away from a parent frequently magnified children's negative self-talk and feelings of being out of control. Even children who didn't describe themselves as taking on parenting roles took on responsibilities for caring for their unwell parent.

“... I felt really capable because maybe I felt like I could see things more clearly than my mum could and that made me feel-sort of in control."

Responsibility was reported as affecting personality, with girls in particular describing having lost a part of their childhood. Older boys maintained distance from their parent by isolating themselves. Responsibility was both emotionally 
negative and positive with children feeling positive about being a support but also feeling guilt for a perceived undermining of their parent.

“... there was a knot that I pushed through and it looked out over the paddock and I used to sit and look through that knot and dream about worlds beyond my shitty little backyard."

\subsubsection{Children's experiences of professionals}

Children reported not being listened to or included in decisions professionals made about their parent's mental illness.

“... they didn't tell me anything that they didn't think I needed to know. . . they never asked me how I was doing."

For the majority, children described being on the periphery of their parent's intervention or at the centre themselves without professionals considering what was going on for their parent.

“... she was actually, a counsellor for my mum, now I think that's bad because she wasn't very understanding of my issues, she was more for my mum. ... yeah it was just for her though not us kids."

Three-quarters were frustrated and angry child protection services had been involved because of issues around parental mental illness. Despite involvement, they felt little action was taken to support them or their parent; instead, a punitive approach was taken by child protection and this in turn added to the stress and deterioration in mental health for everyone in the family.

“... child protection was involved quite frequently. I lost count of how many times which is pretty sad and nothing ever really actually happened. I felt blamed by them for my mum being mad."

Despite a predominantly negative view of support, a few positives did emerge. Key was a support person who was able to listen and take a broader view of children's circumstances. Someone who realised the issues were not just individual, but family based. Where parents saw professionals, who were aware of bidirectional influences, the children reported feeling more supported and understood.

“... they know what's been going on with me and my mum so they understand and they could easily help when me or my mum have a mental breakdown."

Good support people were those children could trust and who would stick by them. These were frequently a peer who was available, understanding and non-judgemental. Often online friends, who were removed from their reality, were most accepting of the strains they faced in having a parent with mental health problems. Boys particularly described on-line friends as helping reduce emotional distress.
“... my online friends... are angels ... they just understand what's going on for me and dad."

\subsubsection{Children's deliberations on support they would have liked}

Consideration of support for other families was a problematic area for the children to conceptualise. However, the most important concepts they illustrated were family time, help with family dynamics, and receiving more information about mental illness. The idea of help early, even in kindergarten, was perceived as necessary. Children also suggested different approaches in schools focusing on helping them understand mental illness in families and addressing the issue of stigma.

“.. counselling and help with more complex issues like family dynamic and stuff... you need help to understand and manage your emotions and stuff."

\section{Discussion}

Four groups of influencing factors can best describe key findings from the interpretative phenomenological analysis. Firstly, children felt parental mental illness was a factor in their feeling rejected and abandoned from a very young age. They reported parents as displaying a lack of attachment or having an angry approach to parenting. Worry about what parents might do next or blaming themselves for any deterioration of their parent's mental health was common. Living in a constant state of uncertainty around parental mood was frequently reported. The current literature indicates child psychological difficulties result from exposure to parental mental illness. ${ }^{[36]}$ Uncertainty increases children's anxiety and impacts on their own mental illness, invariably exacerbating their mood or other symptoms. Confusion over parents' symptoms and presentation adds to children's anxiety. Children in our study described parental mental illness as exacerbating their mental illness though also noting a strong emotional assimilation with their parents.

Secondly, children recognised how their mental illness impacted on relationships inside and outside the family unit. Older children took on parenting roles, and lived in what they described as a state of uncertainty and insecurity. Children sought to control their own mental illness, particularly when a parent was mentally unwell. Such approaches were rarely long term and might reflect two factors: emotional immaturity; and lack of scaffolding from their parent. Lareau ${ }^{[37]}$ suggests children living in poor families have less structure and poorer interactions with less parental engagement. Suggestions from these children indicate a similar process when there is co-existing mental illness in families. Confusion over their own and their parent's mental illness led to resentment and anger which in turn compounded difficulties in the 
child-parent relationship.

Thirdly support was an issue for the children with all the children describing parental support as changeable and inconsistent. Outside of home children sought solace, usually from peers, finding one like-minded peer to share experiences and strategies with. Most found school and professional support a hindrance because of stigma and a lack of understanding of the complexity of their situation. The scarcity of suitable counselling and mental health education was a major barrier for children.

Finally, children described bidirectional factors which were equivalent to a cold or infection transmitted between family members. They recognised how personal mental health issues could push their parent to also become unwell. As parents became unwell so the level of anger and anxiety increased in the children. Anxiety was presented as a key bidirectional influence: each family member uncertain about what to expect from the other, thus intensifying the anxiety. Depression was also presented as significant in families, where the mood of one person had a domino effect, affecting the mood of others in the family. Bidirectional influences did not show solely at the emotional level but also at the behavioural level with children reporting they would invariably find themselves (when mentally unwell) behaving just like their parent.

The strategies children utilised included time away from others. In those families where family time was used, this approach was felt to be essential for reducing bidirectional influences of mental illness (see Figure 2). Where this approach was established, children felt they were understood and listened to by their parent. Use of family time helped reduced the overall stress in the family.

Whilst little research exists on how children understand their own mental illness, the children in this study described their mental illness as a reflection of their parents. This important clue for intervention appears to be absent in current clinical discussions. Often CAMHS clinicians are drawn into parents' own concerns rather than those of the children. Children may have limited understanding of mental illness and with parents' present their responses might be inhibited. ${ }^{[38]}$ How much more might the influence of parental menal illness have on children's responses?

Children's accounts reiterate widely known difficulties relating to school, community and supports. Social and school problems may increase a child's anxiety. ${ }^{[39]}$ Children in this study felt school staff did not know how to manage the issues of child and parent mental illness likely due to a lack of training. ${ }^{[40,41]}$ It has been found that $61.5 \%$ of children suffer bullying because of their mental illness. ${ }^{[42]}$ From these children's accounts such bullying is amplified by parents also having a mental illness.

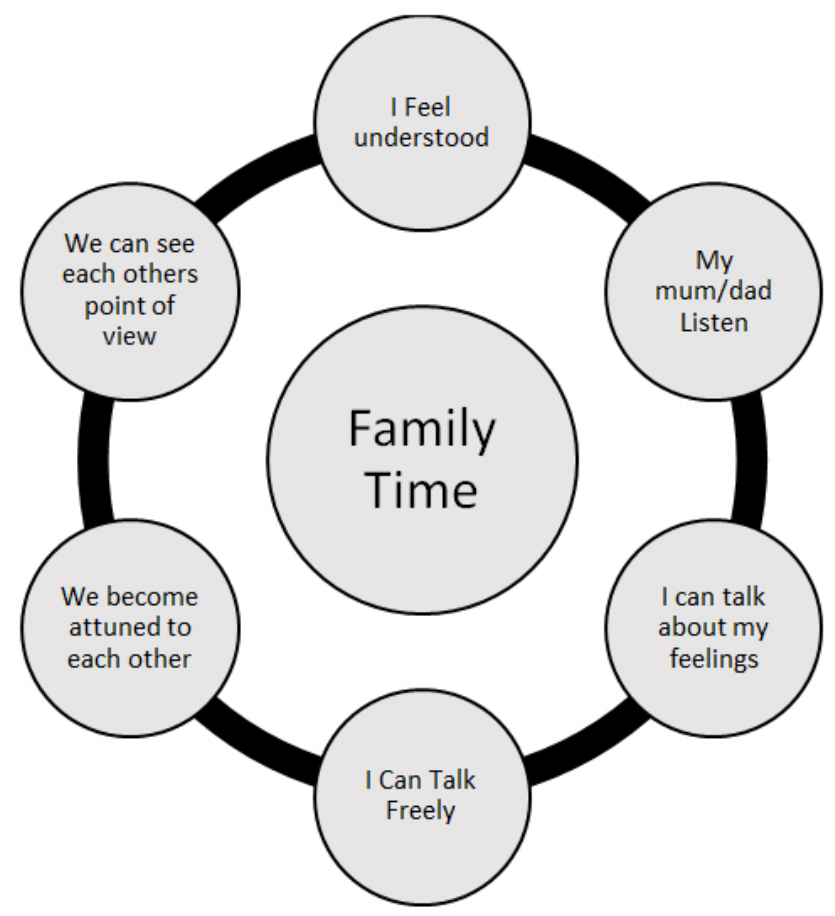

Figure 2. Family time as a process to reduce bidirectional impacts of mental illness

Stigma for children with mental illness, although levels are significant, is not well conceptualised and may occur for even very young children. ${ }^{[43]}$ Indeed, children in this study noted stigma as problematic both in school and with peers. Furthermore, they reported the stigma relating to their parent's mental illness also impacted on peer friendships. It would appear from the accounts of these children, that addressing stigma requires a multimodal approach incorporating early intervention aimed at younger children. For some of these children social isolation and avoiding school was preferable to experiencing mental illness stigma. Children described school avoidance as a key coping strategy which met two goals: avoiding bullying; and allowing them to support their parent at home. Undoubtedly a novel approach is needed to address this problem. Schools frequently describe their environment as for "learning" and suggest social and emotional issues are a family responsibility. It would seem that this argument lacks strength in the mainstream discourse when considering children living in a family with co-existing mental illness. In this study, the children highlighted lack of school support as an issue, which has been emphasised by other research in this area. ${ }^{[44-46]}$

Where a high level of support existed children felt positive about school and the attitudes of the school staff to mental ill- 
ness. Children in this study suggested schools' access more mental health assistance and support for children, families and staff. Universal school programmes on mental health problems can have a positive impact on how children cope and on their level of anxiety. ${ }^{[47]}$ A focal point for intervention might be on providing psycho-education to school staff on issues relating to the bidirectional effects of mental illness. It would seem important for teachers, particularly senior school staff, to gain an awareness of the complexities and demands faced by children where there is coexisting mental illness. Also important is for teachers to understand how to support a reduction in children's anxiety.

Where parents needed to go into hospital, children reported being overlooked and not informed of what was happening, adding to their distress. This perception of children, that their emotions were not considered when a parent was admitted to hospital emphasises a significant gap in service delivery. Not feeling listened to was repeatedly highlighted, with children feeling that they were considered as individuals, not as individuals within a family. Children felt this individualistic view failed to recognise the bidirectional influences of mental illness in the family. Two-thirds of the children felt professionals wanted to direct rather than engage with them. Such approaches suggest some gaps may exist in how mental health clinicians understand children who lives in families with intergenerational mental illness. Notably parental mental illness was either not considered or was given little weight by children's clinicians. The lack of psychoeducation appears to be a significant gap hindering children's resilience. The importance for these children of wanting their or their parent's clinician to take a broader view cannot be underestimated, and their descriptions suggest an important gap in the way professionals think about co-existing mental illness in families. For the children we interviewed they did not feel empowered in their recovery journey. Part of the problem may be rooted in the dearth of literature in this area. Supporting family units, and seeing further than just the child or parent, is signified as important for enhancing children's mental health and supporting family recovery. Important for this discussion is the notion of "linked collaborative services". ${ }^{[18]}$ (p. 55) Services connected with and alert to all people in families with mental health problems to enable intervention to be effective.

\section{STUdY Limitations}

Families were recruited through clinician recommendation, a methodology dependent on clinicians' selection of families for this study. Whilst recognising the children tended to follow the initial prompts it was clear in the narrative they were open and expansive in their interpretations and consciousness.
Such was this, insider perspective, it was possible to obtain a rich and valuable insight into what is normally a very private and protected family world. Although limited in size this regional and rural sample of children provided a valuable and informative description, an account delivered with a passion founded on these children's wide-ranging experiences.

\section{THE BIDIRECTIONAL IMPACTS}

The children in this study highlight two key points: The need for bidirectional influences to be considered, and the need for specific strategies to help families address bidirectional effects. As co-existing mental illness was a criteria for this research it was foreseeable that bidirectional impacts of mental illness might arise as a key theme. Regardless of their diagnosis children reported a bipartite connection between their own and their parent's mental illness. Children felt strongly impacted by their parent when the latter became unwell, and they recognised how a deterioration in their mental illness influenced their parent. Anxiety and mood issues dominated as important bidirectional influences with all the children describing a corollary effect. Despite having significant mental illnesses, themselves children described having experienced bidirectional transference as more significant when they were younger. Whilst unclear from these interviews why this might be the case it is possible that older children are better able to adapt to the situation they find themselves in and are better able to articulate for support from peers and others.

Two important aspects were revealed in the interplay between children and parents. Firstly, children felt parentified to keep the home environment functioning. For some they took on caring roles. Secondly when parents became unwell children would try to subdue their own mental health concerns to try and ease parental distress and to protect siblings. Children described such strategies as rarely working with invariably children's mental health deteriorating in line with their parents.

\section{Conclusions}

Children born into families where there is mental illness may have an arduous journey from the day they are born. Attachment issues can be significant with bidirectional influences of mental illness contriving to change the experiences of childhood. In addition to managing their mental illness, children experience stigma and denunciation for their and their parent's mental illness. There is little if any information given to these children and supports emphasise individual rather than family systems. From these children's accounts, bidirectional impacts of mental illness are not usually contemplated by mental health services. With inadequate sup- 
port and incomplete intervention, children adapt to be able to manage. Tackling how families with concurrent mental illness are supported and how interventions address bidirectional influences need to be primary in future consideration for helping families. This research has exposed significant gaps in provision for families where there is co-existing mental illness and highlights the need for greater attention to bidirectional influences. Education of children about their parent's mental illness can occur at an early age and so empower children and lessen stress and mental health problems. There needs to be greater emphasis on training clinicians in the understanding of bidirectional impacts of mental ill-

\section{REFERENCES}

[1] Maybery D, Reupert A. Parental mental illness: A review of barriers and issues for working with families and children. Journal of Psychiatric and Mental Health Nursing. 2009; 16: 784-791. PMid: 19824972. https://doi.org/10.1111/j.1365-2850.2009.0 1456. $\mathrm{x}$

[2] Leijdesdorff S, van Doesum K, Popmac A, et al. Prevalence of psychopathology in children of parents with mental illness and/or addiction: an up to date narrative review. Current Opinion in Psychiatry. 2017; 30: 312-317. PMid: 28441171. https ://doi .org/10.109 7/YCO. 0000000000000341

[3] Rasic D, Hajek T, Uher R. Risk of Mental Illness in Offspring of Parents with Schizophrenia, Bipolar Disorder, and Major Depressive Disorder: A Meta-Analysis of Family High-Risk Studies. Schizophrenia Bulletin. 2014; 40: 28-38. PMid: 23960245. https://doi.org/10.1093/schbul/sbt114

[4] Maybery D, Reupert A. The number of parents who are patients attending adult psychiatric services. Current opinion in Psychiatry. 2018; 31(4): 358-362. PMid: 29847344. https://doi.org/10.1 $097 /$ YCO 0000000000000427

[5] Hearle J, Plant K, Jenner L, et al. A survey of contact with offspring and assistance with child care among parents with psychotic disorders. Psychiatric Services. 1999; 50(10): 1354-1356. PMid: 10506307. https://doi.org/10.1176/ps.50.10.1354

[6] Gatsou L, Yates S, Hussain S, et al. Parental Mental Illness: Incidence, Assessment and Practice. Mental Health Practice. 2016; 19(5): 25-27. https://doi.org/10.7748/mhp.19.5.25.s18

[7] Benders-Hadi N, Barber M, Alexander MJ. Motherhood in Women with Serious Mental Illness. Psychiatric Quarterly. 2013; 84: 6572. PMid: 22576070. https://doi .org/10.1007/s11126-012 $-9227-1$

[8] Östmann M, Kjellin L. Stigma by Association: Psychological Factors in Relatives of People with Mental Illness. British Journal of Psychiatry. 2002; 181: 494-498. https://doi.org/10.1192/bj p.181.6.494

[9] Jessop ME, De Bondt N. A consultation service for Adult Mental Health Service clients who are parents and their families. Advances in Mental Health. 2012; 10(2): 149-156. https://doi.org/10.5 172/jamh.2011.10.2.149

[10] Van Veen SC, Batelaan NM, Wesseldijkj LW, et al. Psychiatric disorders within families: an integrated approach through the family clinic. Tijdschrift Voor Psychiatrie. 2016; 58(2): 95-105. PMid: 26881342. ness. Children and parents do not operate in isolation but are part of a system that has consequence affects. Challenging stigma, providing prompt education, full family engagement and early involvement by mental health services are essential for these children. A stronger emphasis on family-based approaches and integrated service provision, with attention to bidirectional impacts, may help minimise mental health problems for children living with a parent who has a mental illness. With limited investigations into bidirectional impacts of mental illness, this is an area needing further exploration.

\section{CONFlicts OF INTEREST Disclosure}

The authors declare they have no conflicts of interest.
[11] Amiri S, Ghoreishizadeh MA, Alavizadeh Y, et al. Lifetime prevalence of psychiatric disorders among parents of children with bipolar 1 disorder: Parental difference. The Scientific World Journal. 2014. PMid: 25431782. https ://doi .org/10.1155/2014/256584

[12] Baker L, Lees R. Parental Mental Illness and Coping: An Exploratory Survey. Canadian Journal of Family and Youth. 2014; 6(1): 115-133.

[13] Naughton MFA, Maybery D, Goodyear M. Prevalence of mental illness within families in a regional child-focused mental health service. International Journal of Mental Health Nursing. 2017; 901-910. PMid: 28929573.

[14] van Santvoort F, Hosman CMH, Janssens JMAM, et al. The Impact of Various Parental Mental Disorders on Children's Diagnoses: A Systematic Review. Clinical Child and Family Psychology Review. 2015; 18: 281-299. PMid: 26445808. https://doi .org/10.100 7/s10567-015-0191-9

[15] Göpfert M, Webster J, Seeman MV, Eds. Parental psychiatric disorder: Distressed parents and their families. Cambridge: Cambridge University Press; 2004. https://doi.org/10.1017/CB097805 11543838

[16] Boursnell M. Assessing the capacity of parents with mental illness and risk. International Social Work. 2014; 57: 92-108. https: //doi.org/10.1177/0020872812445197

[17] Hautamäki A. Attachment and parental sensitivity in a low-risk Finnish sample - The avoidant and unresponsive Finns? Piaget is dead, Vygotsky is still alive, or? A book in Honour of Professors Airi and Jarrko Hautamaki. P. Aunio, M. Jahnukainen, M. Kalland and J. Silvonen. Finnish Educational Research Association, Research in Education Sciences. 2010; 149-182.

[18] Falkov A. The Family Model Handbook: An integrated approach to supporting mentally ill parents and their children. Hove, Pavillion Publishing; 2012. PMid: 23054375.

[19] Paul NL, Byfield PB. A Marital Puzzle, Transgenerational Analysis in Marriage Counselling. New York, W.W. Norton \& Company; 1975.

[20] Benoit D, Parker K. Stability and transmission of attachment across three generations. Child Development. 1994; 65: 1444-1456. PMid: 7982361. https://doi.org/10.2307/1131510

[21] Dozier M, Stovall KC, Albus KE, et al. Attachment for infants in foster care: the role of caregiver state of mind. Child Development. 2001; 72(5): 1467-1477. PMid: 11699682. https ://doi .org/10 $.1111 / 1467-8624.00360$ 
[22] Shah PE, Fonagy P, Strathearn L. Is attachment transmitted across generations? The plot thickens. Clinical Child Psychology and Psychiatry. 2010; 15(3): 329-346. PMid: 20603421. https ://doi.or $\mathrm{g} / 10.1177 / 1359104510365449$

[23] Crittenden PM, Landini A. Assessing adult attachment: A dynamic maturational approach in discourse analysis. New York: Norton; 2011.

[24] Bailey HN, Tarabulsy GM, Moran G, et al. New insight on intergenerational attachment from a relationship-based analysis. Development and Psychopathology. 2017; 29: 433-448. PMid: 28401837. https://doi.org/10.1017/S0954579417000098

[25] James A, Prout A. Re-presenting childhood: Time and transition in the study of childhood. Constructing and reconstructing childhood: Contemporary issues in the sociological study of childhood. A. James and A. Prout. Basingstoke: Falmer Press; 1990.

[26] Smith AB, Taylor N. The sociocultural context of childhood: Balancing dependency and agency. Children's voices: Research, policy and practice. A. B. Smith, N. J. Taylor and M. Gollop. Auckland: Pearson Education; 2000.

[27] Smart C, Neale B, Wade A. Rethinking childhood; Rethinking families. Cambridge: Polity Press; 2001.

[28] Dunn J, Brown J, Beardsall L. Family talk about feeling states and children's later understanding of others' emotions. Developmental Psychology. 1991; 27(3): 448-455. https ://doi.org/10.1037/ 0012-1649.27.3.448

[29] Morss JR. The several social constructions of James, Jenks, and Prout: A contribution to the sociological theorization of childhood. International Journal of Children's Rights. 2002; 10: 39-54. https://doi.org/10.1163/157181802772758119

[30] Matthews SH. A window on the 'new' sociology of childhood. Sociology Compass. 2007; 1(1): 322-334. https ://doi .org/10.111 $1 / \mathrm{j} .1751-9020.2007 .00001 . \mathrm{x}$

[31] Jenks C. Childhood. New York: Routledge; 1996. https ://doi.or g/10.4324/9780203129241

[32] Corsaro WA. We're friends right? Inside kids' culture. Washington, DC: Joseph Henry Press; 2003.

[33] Rogers C. Client-centered therapy: Its current practice, implications and theory. London: Constable; 1951.

[34] Overcash JA. Narrative research: a review of methodology and relevance to clinical practice. Critical reviews in Oncology/Hematology. 2003; 48: 179-184. PMid: 14607381. https://doi.org/10.101 6/j.critrevonc. 2003.04.006

[35] Braun V, Clarke V. Using thematic analysis in psychology. Qualitative Research in Psychology. 2006; 3(2): 77-101. https://doi.or $\mathrm{g} / 10.1191 / 1478088706 \mathrm{pp} 063 \mathrm{oa}$
[36] Simpson-Adkins GJ, Daiches A. How Do Children Make Sense of their Parent's Mental Health Difficulties: A Meta Synthesis. Journal of Child and Family Studies. 2018. PMid: 30147287. https : //doi.org/10.1007/s10826-018-1112-6

[37] Lareau A. Unequal childhoods: Class, race, and family life. Berkeley, University of California Press; 2003.

[38] Stafford V, Hutchby I, Karim K, et al. "Why are you here?" Seeking children's accounts of their presentation to Child and Adolescent Mental Health Service (CAMHS). Clinical Child Psychology and Psychiatry. 2016; 21(1): 3-18. PMid: 25062687. https : //doi .org/10.1177/1359104514543957

[39] Platt R, Williams SR, Ginsburg GS. Stressful Life Events and Child Anxiety: Examining Parent and Child Mediators. Child Psychiatry and Human Development. 2016; 47(1): 23-34. PMid: 25772523. https ://doi.org/10.1007/s10578-015-0540-4

[40] Bibou-Nakou I. Helping teachers to help children living with a mentally ill parent. School Psychology International. 2004; 25(1): 42-58. https://doi.org/10.1177/0143034304041502

[41] Reupert A, Maybery D. Families affected by parental mental illness: A multiperspective account of issues and interventions. American Journal of Orthopsychiatry. 2007; 77: 362-369. PMid: 17696664. https://doi.org/10.1037/0002-9432.77.3.362

[42] Dyer K, Teggart T. Bullying Experiences of Child and Adolescent Mental Health Service-users: A Pilot Survey. Child Care in Practice. 2007; 13(4): 351-365. https ://doi .org/10.1080/1357527070 1488733

[43] Mukolo A, Hefinger CA, Wallston KA. The Stigma of Childhood Mental Disorders: A Conceptual Framework. Journal of the American Academy of Child and Adolescent Psychiatry. 2010; 49(2): 92-103. PMid: 20215931.

[44] Atkins MS, Hoagwood KE, Kutash K, et al. Toward the integration of education and mental health in schools. Administration and Policy in Mental Health. 2010; 37(1-2): 40-47. PMid: 20309623. https : //doi.org/10.1007/s10488-010-0299-7

[45] Overstreet S. A school-based assessment of secondary stressors and adolescent mental health 18 months post-Katrina. Journal of School Psychology. 2010; 48(5): 413-431. PMid: 20728690. https : //doi.org/10.1016/j.jsp.2010.06.002

[46] Crockett J. There's nothing the *\#! wrong with me. Youth Studies Australia. 2012; 31(1): 53-59.

[47] Collins S, Woolfson LM, Durkin K. Effects on coping skills and anxiety of a universal school-based mental health intervention delivered in Scottish primary schools. School Psychology International. 2013; 35(1): 85-100. https://doi.org/10.1177/0143034312 469157 